\title{
The use of autologous serum for the treatment of ocular surface disease at a Swedish tertiary referral center
}

This article was published in the following Dove Press journal:

International Medical Case Reports Journal

2 March 2016

Number of times this article has been viewed

\author{
Joanna von Hofsten ${ }^{1,2}$ \\ Maria Egardt ${ }^{2}$ \\ Madeleine Zetterberg ${ }^{2-4}$ \\ 'Department of Ophthalmology, \\ Halland Hospital Halmstad, Halmstad, \\ ${ }^{2}$ Department of Ophthalmology, \\ Sahlgrenska University Hospital, \\ Mölndal, ${ }^{3}$ Department of Clinical \\ Neuroscience and Rehabilitation, \\ ${ }^{4}$ Department of Ophthalmology, \\ Institute of Neuroscience and \\ Physiology, The Sahlgrenska \\ Academy, University of Gothenburg, \\ Gothenburg, Sweden
}

Purpose: The study aims to describe an intact cohort with mixed ocular surface disease (OSD) treated with autologous serum (AS) eye drops in a tertiary eye center.

Patients and methods: All cases ( $\mathrm{n}=32$ eyes, 24 patients) treated with AS for OSD at the Department of Ophthalmology, Sahlgrenska University Hospital, Mölndal, between 2002 and 2013 were included and medical records were reviewed retrospectively.

Results: Mean duration of treatment with $20 \%$ AS was $28.3 \pm 56.1$ (median: 12 , range: $3-217$ ) days. The most common indication for AS treatment was a persistent epithelial defect (PED), which was seen in 16 eyes of 14 patients. Mean duration of PED prior to treatment was $19.3 \pm 18.9$ (median: 10, range: 5-68) days. Complete or partial epithelial healing occurred in nine eyes $(56.2 \%)$. The remaining seven eyes $(44 \%)$ did not respond to treatment or data were missing. The second group consisted of nine eyes of five patients with superficial punctate keratitis (SPK) secondary to dry eye syndrome. Complete or partial healing of the epithelium occurred in five eyes (56\%), and the remaining four eyes (44\%) were lost to follow-up. A third group included five eyes with AS as an adjuvant treatment after corneal perforation, whereas a fourth group consisted of one patient with dry eye after laser-assisted in situ keratomileusis (LASIK).

Conclusion: In this cohort, patients with PED or SPK responded well to treatment with AS. Standardized preparation protocols, defined optimal serum concentrations for various indications, and large randomized clinical trials are needed to fully comprehend the role of AS in the treatment of OSD.

Keywords: dry eye syndrome, persistent epithelial defect, superficial punctate keratitis

\section{Introduction}

Ocular surface disease (OSD) can be challenging for ophthalmologists worldwide. Disturbances affecting the delicate balance among cornea, tear film, and conjunctiva are studied with the aim of optimizing treatment for the specific patient. The loss of epithelial integrity of the cornea may initiate processes resulting in inflammation, melting, and perforation. Conditions that may lead to nonhealing epithelial defects include keratoconjunctivitis sicca (eg, Sjögren's syndrome), Stevens-Johnsons syndrome, mucous membrane pemphigoid, neurotrophic cornea (herpes, diabetes), exposure keratitis, stem cell failure, etc. A healthy tear film provides the cornea and conjunctiva with essential components needed to maintain stability. Epidermal growth factor (EGF), nerve growth factor (NGF), vitamin A, and transforming growth factor $\alpha$ and $\beta$ (TGF- $\alpha$ and $-\beta$ ) are present in tears and confer important proliferative effects on the epithelium. ${ }^{1-6}$ Fibronectin has been suggested to be a scaffold that promotes epithelial healing by facilitating cell attachment. ${ }^{7}$ Reduction of these epitheliotrophic factors due
Correspondence: Joanna von Hofsten Department of Ophthalmology, Halland Hospital Halmstad, SE-30I 85 Halmstad, Sweden

Tel +4635147796

Fax +46 35I5 8205

Email joanna.vonhofsten@regionhalland.se
International Medical Case Reports Journal 2016:9 47-54

Dovepress

http://dx.doi.org/10.2147/IMCRI.S97297 (c) (1) (5) 2016 von Hofsten et al. This work is published and licensed by Dove Medical Press Limited. The full terms of this license are available at https://www.dovepress.com/ work you hereby accept the Terms. Non-commercial uses of the work are permitted without any further permission from Dove Medical Press Limited, provided the work is properly attributed. For
terms permission for commercial use of this work, please see paragraphs 4.2 and 5 of our Terms (https://www.dovepress.com/terms.php).
s. 
to disease can lead to epithelial defects. Serum is the fluid part of blood devoid of its cellular components. It contains several growth factors, many in higher concentrations compared to that in tears. ${ }^{8,9}$ In keeping with this, application of human serum appears to be a logical regimen to treat OSD.

The first report on using autologous serum (AS) in patients with eye disease was published in 1975. Ralph et $\mathrm{al}^{10}$ investigated the use of a mobile perfusion pump with different fluids (among them, diluted serum) to moisten dry eyes of 12 patients. Nine years later, Fox et $\mathrm{al}^{11}$ used diluted AS in comparison to saline solution in patients with keratoconjunctivitis sicca with favorable results. Despite these results, the treatment did not gain popularity for a number of years until the late 1990s, when several clinical studies on the subject were conducted. ${ }^{12}$ The purpose of this study is to describe the use and outcome of topical treatment with AS in a nonselected cohort of patients with moderate-to-severe OSD at a Swedish tertiary referral center.

\section{Materials and methods}

A retrospective study was conducted to evaluate all patients treated with AS drops at the Department of Ophthalmology, Sahlgrenska University Hospital, Mölndal, Sweden. During the period of January 2002 to May 2013, 32 eyes of 24 patients received treatment with AS drops. Because one of the purposes of the study was to describe an unselected patient group and the spectrum of indications for AS treatment at a tertiary referral center, no patients were excluded from analysis on grounds of insufficient medical records or because they were lost to follow-up. Four main groups could be identified on the basis of biomicroscopy findings: 1) patients with a persisting epithelial defect (PED) that did not heal in the expected period of time; 2) dry eyes showing superficial punctate keratitis (SPK); and 3) a group of patients with corneal perforations receiving AS as adjuvant treatment. For patients with overlapping conditions or patients exhibiting several of the above-mentioned signs, the most severe condition was chosen as the basis for classification. One patient, treated under the diagnosis of severe post-laserassisted in situ keratomileusis (LASIK) pain with moderate signs of dry eye, constituted a fourth group. Clinical data on indications for treatment, duration of OSD, and previous and simultaneous treatment for OSD were retrieved from medical records. Data were also collected on duration and frequency of treatment with AS, as well as on ocular findings prior to treatment and at last follow-up. Outcome measures included the proportion of patients with healed corneal epithelium and time to healing. The study was approved by the Regional
Ethics Committee in Gothenburg, and the tenets of the Declaration of Helsinki were followed. Informed patient consent was not required according to the Regional Ethics Committee in Gothenburg, as this was a retrospective study.

\section{Treatment protocol}

AS drops were prepared by taking $10 \mathrm{~mL}$ of peripheral blood from each patient. The samples were allowed to clot for 30 minutes and were then centrifuged for 9 minutes at $2,900 \times g$. Serum was extracted under sterile conditions. The serum $(2 \mathrm{~mL})$ was diluted with $8 \mathrm{~mL}$ of saline solution for a final concentration of $20 \%$. One patient who did not respond to $20 \%$ serum was also treated with $100 \%$ serum. No testing for blood-borne diseases was performed. Antibiotics were not added to the solution but were included in the treatment regimen in 24 of 32 eyes. The bottles were frozen at $-20^{\circ} \mathrm{C}$ and patients were instructed to store bottles in the freezer, keep current bottle in the refrigerator, and discard it after 1 day. Dosage of drops varied between patients from two to eight times daily, as shown in Table 1.

\section{Results}

Treatment with AS for OSD was introduced in January 2002 at the Sahlgrenska University Hospital. All 24 patients (32 eyes) treated with AS until May 2013 were included in the study. Clinical characteristics of the patients are given in Table 1, listed consecutively as they were put on AS treatment. Mean age of the patients at initiation of treatment was 56.5 \pm 24.5 (median: 57.5; range: 14-92) years and the male/ female ratio was 1:2. All patients were given $20 \%$ AS as eye drops at the first treatment. One patient had 100\% AS drops in a subsequent treatment episode. The frequency of applying serum varied among patients, although 84\% (27 eyes) were prescribed drops three to four times daily. Mean treatment duration was $28.3 \pm 56.1$ (median: 12 ; range: $3-217$ ) days. None of the patients had any adverse effects related to treatment. As described earlier, patients were classified on the basis of biomicroscopy findings, resulting in four subgroups, each comprising several underlying ocular and/or systemic conditions (Table 1). A summary of the outcome and follow-up period for all groups treated with AS is presented in Table 2.

\section{Persistent epithelial defects}

The etiology of PED is presented for each eye in Table 1. Six out of 16 eyes had neurotrophic corneas. Three eyes were dry, one of those suffering from Schnitzler's syndrome. Three eyes had primary exposure keratitis, in two eyes due to thyroid-associated ophthalmopathy and in one patient 


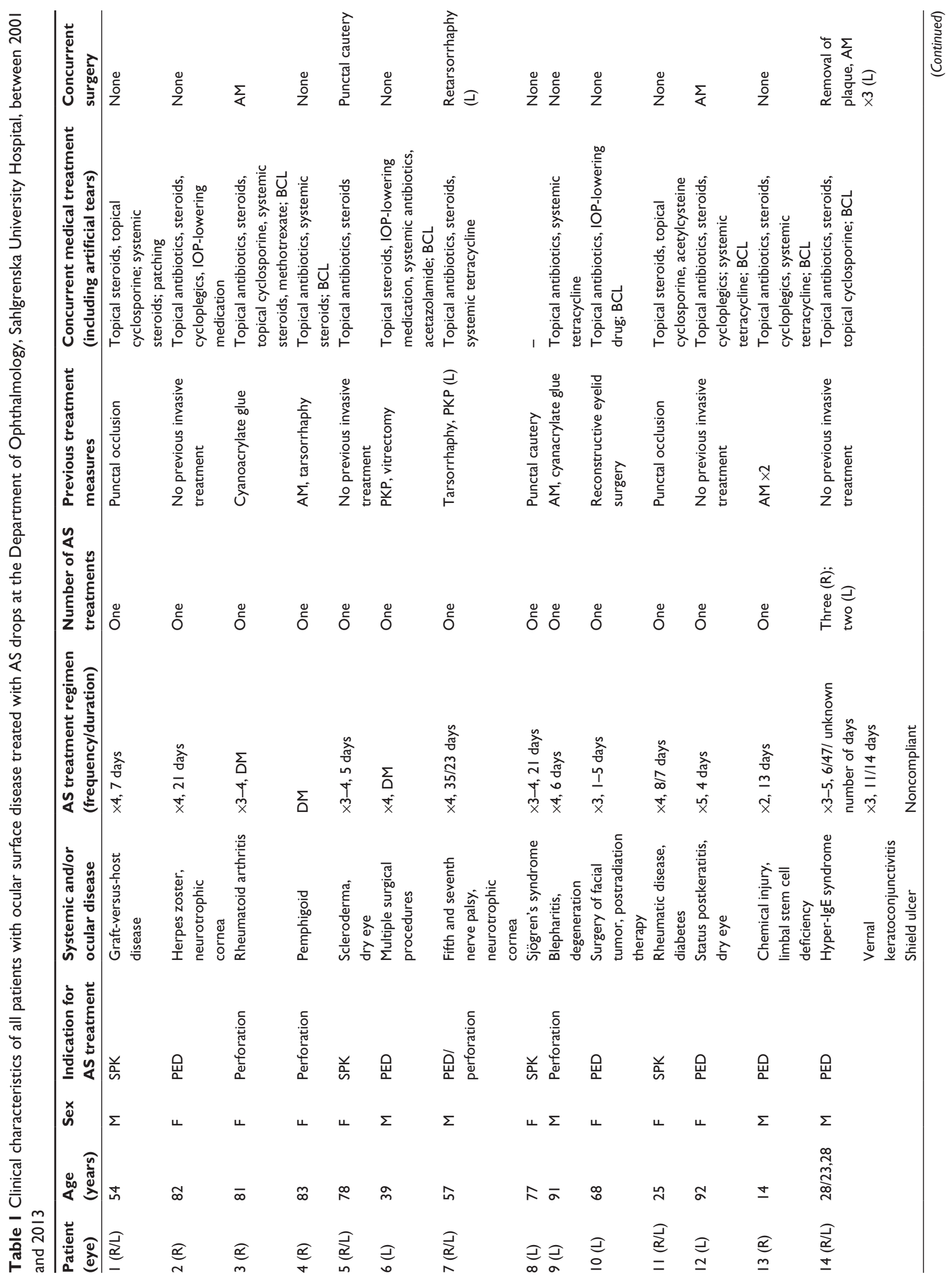




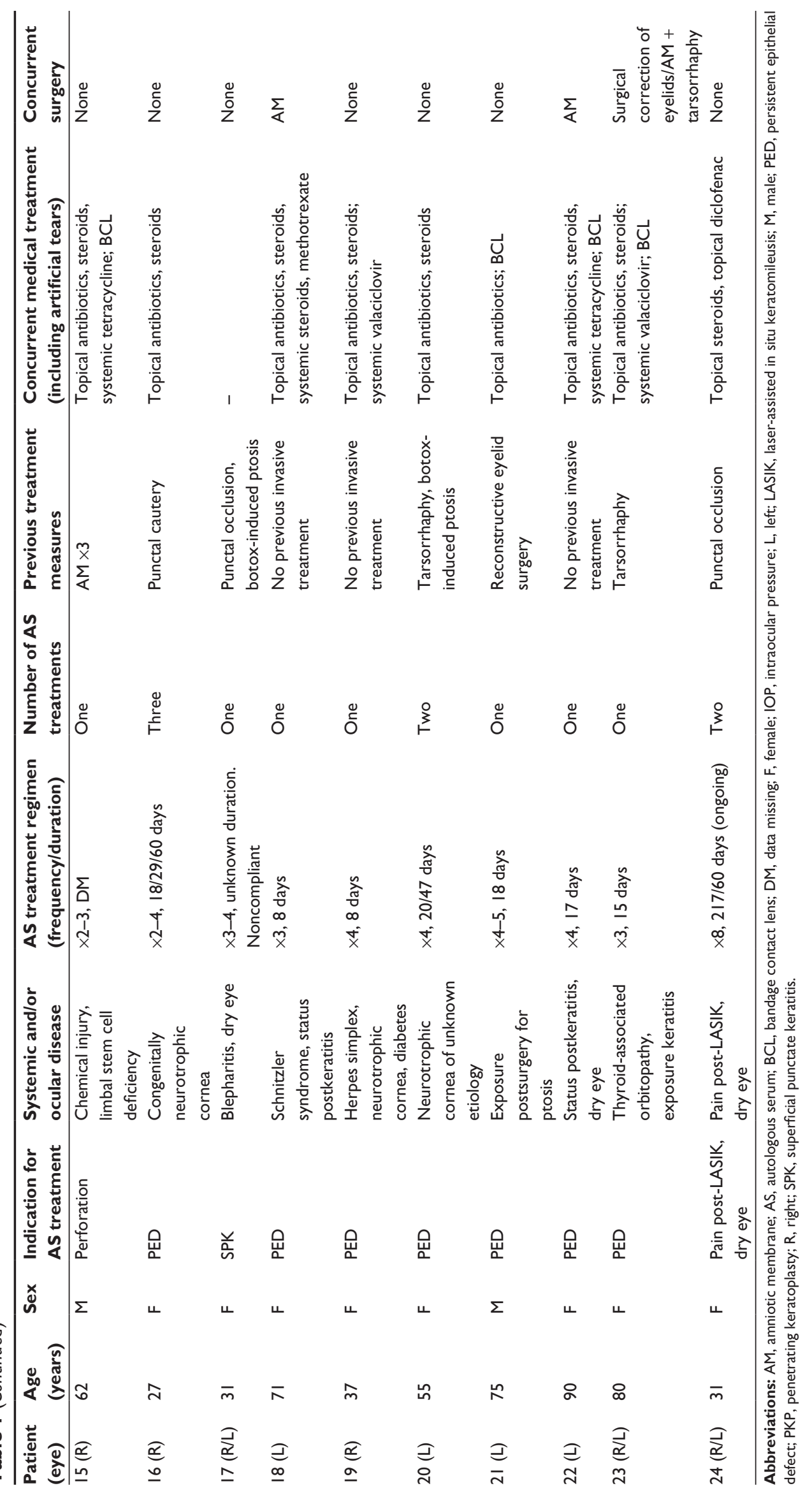


as a consequence of previous ptosis surgery. Limbal stem cell deficiency was diagnosed in one eye that had previous chemical injury. One eye had received local radiation for maxillary tumor and had eyelid abnormalities combined with loss of corneal sensitivity. Two eyes of one patient included in this group were subsequently diagnosed as having a shield ulcer associated with vernal keratoconjunctivitis. The mean duration of PED before the first treatment was 19.3 \pm 18.9 (median: 10; range: 5-68) days. Time to complete healing was $9.2 \pm 18.9$ (median: 6 ; range: $3-16$ ) days, which occurred in six (37.5\%) eyes. Partial healing occurred in three (18.8\%) eyes and was followed by application of amniotic membrane at days 3,5 , and 14 , respectively. The remaining seven eyes did not show any healing or the data from medical journals were not interpretable. Two of these seven eyes had amniotic membrane transplantation during the first days of treatment, which precluded assessment of healing. Two patients (three eyes) were denoted as noncompliant.

\section{Superficial punctate keratitis}

Nine eyes of five patients were treated with AS because of refractory SPK in dry eye syndrome. Complete success with regression of fluorescein staining was achieved in three eyes in 7/7/15 days during treatment (Table 2). Partial success with less-extensive SPK was observed in two eyes. The remaining two patients (four eyes) were lost to follow-up. Seven eyes had occlusion of puncti (plugs or diathermia) before treatment, five of those in close conjunction with initiation of AS treatment. Two eyes had diathermal occlusion during treatment. All patients received artificial tears frequently. Patient 1 had addition of cyclosporine in the treatment regimen and patient 11 received acetylcysteine topically during treatment. No patients had bandage contact lenses before or during treatment.

\section{Perforation}

Five eyes of five patients received AS as adjuvant treatment after perforation of the cornea. The etiology of perforation is outlined in Table 1. In four cases, amniotic membrane transplantation was carried out prior to, simultaneously, or after AS treatment. In Case 7, a tectonic penetrating keratoplasty was conducted before treatment, and Case 15 ultimately needed an allogenic limbal stem cell transplant.

\section{Post-LASIK dry eye/pain syndrome}

One patient could not be classified into any of the abovementioned groups. This 31-year-old woman underwent LASIK surgery 7 years earlier due to contact lens intolerance.

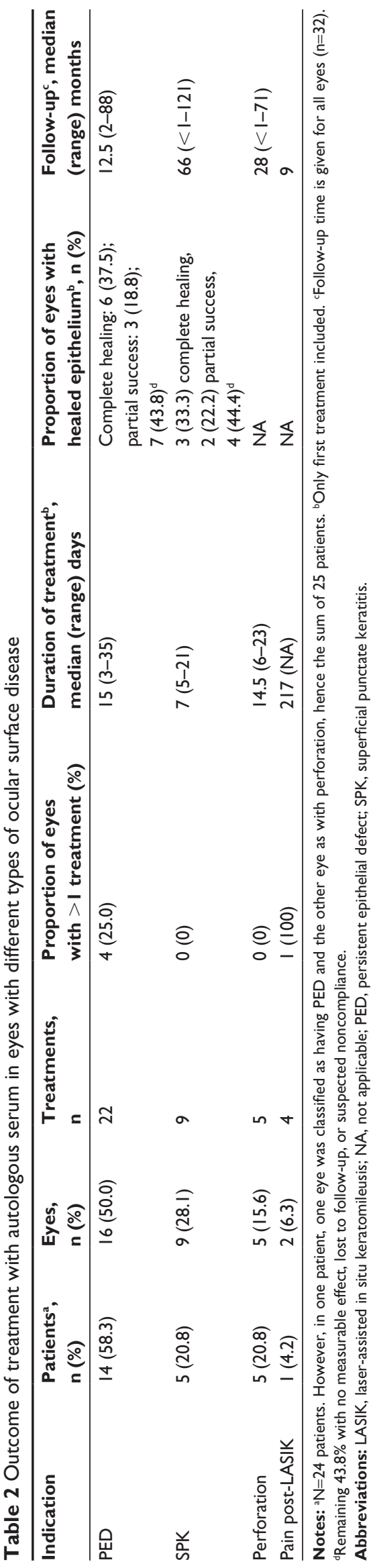


Postoperatively she suffered from persistent irritation, ocular pain, and photophobia. There were moderate signs of dry eye syndrome without epithelial defects. AS drops (20\%) were prepared and given in combination with insertion of punctal plugs. The patient experienced symptomatic relief in terms of sense of dryness, while ocular pain did not respond to treatment. However, a preparation of $100 \%$ serum further decreased the symptoms.

\section{Discussion}

The aim of this study was to present all patients treated with AS at Sahlgrenska University Hospital since the introduction of AS as a treatment option at this clinic. Being a retrospective study, patients were offered other treatments simultaneously to hasten recovery. In the PED group, ten of 16 eyes were treated with bandage contact lenses simultaneously, a combination that has been shown to facilitate epithelial migration. ${ }^{13}$ In the SPK group, occlusion of puncti was performed in seven of nine eyes in close conjunction to or during AS treatment. The remaining two eyes had punctal occlusion earlier during the course of disease. This approach is likely to have influenced the outcome. Ogawa et al ${ }^{14}$ presented 14 patients suffering from graft-versus-host disease treated with AS, seven of them requiring additive punctal plugs to maintain epithelial integrity, whereas Kojima et a ${ }^{15}$ included only patients without punctal occlusion to evaluate the solitary effect of AS drops.

In this cohort, AS was given with a mean duration of treatment of 28.3 (median: 12) days, which is considerably shorter compared to several other studies. ${ }^{15-19}$ In the PED group, this may be explained by an early intervention with amniotic membrane transplantation. An active approach is also reflected by the mean duration of PEDs before treatment in this study: 19.3 (median: 10) days, compared to similar studies with mean 22.4-204 days. ${ }^{13,17,19,20}$

Recently, a Cochrane review was published investigating topical AS as treatment in dry eye syndrome. ${ }^{21}$ Out of 330 reports, only four trials were included in the investigation. In addition to the lack of prospective randomized controlled trials, there is an issue of different treatment protocols. In the present study, a concentration of $20 \%$ AS was used. Diluting the serum was advocated by Tsubota et $\mathrm{al}^{9}$ in 1999 , based on measurements of fivefold increased levels of TGF- $\beta$ in undiluted serum compared with that in tears. Because of the known antiproliferative effect of TGF- $\beta,{ }^{22}$ the solution was diluted to produce a more tear-like product. Despite this, in clinical practice, higher concentrations - up to $100 \%$ - have been successfully used and, on the contrary, seem to speed up epithelial closure. ${ }^{23}$ The explanation for this could be possible proliferative effects of TGF- $\beta,{ }^{22}$ differences in serum growth factor levels among individuals, or variations in the serum preparation procedure. Different time durations and forces used in the centrifugation procedure result in different concentrations of growth factors. Geerling et $\mathrm{al}^{8}$ showed a fivefold decrease in TGF- $\beta$ concentration compared to Tsubota et al's ${ }^{9}$ previous measurements, using higher force and longer time of centrifugation. The variation in concentrations of growth factors in different studies renders comparisons difficult; the frequency of application is another factor that varies among studies. Attempts have been made to standardize the protocols of serum production. ${ }^{24,25}$

The patients in this study were prescribed AS drops three to four times daily in a majority of cases (27 eyes, $84.4 \%$ ). Comparable studies present application frequencies of five to ten times daily. ${ }^{9,11,13-18,20}$ The different drop regimen in this study can be explained by an initial lack of experience in treatment with AS and because of concomitant treatment. The stability of growth factors during storage is another factor to consider. EGF, NGF, TGF- $\beta$, fibronectin, and vitamins A and $\mathrm{E}$ have shown stability in samples stored up to 6 months at $-20^{\circ} \mathrm{C}$ and 1 week at $+4^{\circ} \mathrm{C} .{ }^{26,27}$ Calcitonin gene-related peptide and substance $\mathrm{P}$ were degraded at $+4^{\circ} \mathrm{C}$ in 24 hours. ${ }^{26}$ The stability did not depend on serum dilution because results were similar for $20 \%, 50 \%$, and $100 \%$ serum. $^{27}$

Topical application of AS requires safety considerations. There were no adverse effects during treatment in this patient group. Very few complications are reported in the literature. Cases of keratitis, conjunctivitis, or eyelid eczema could possibly be related to treatment with serum. ${ }^{14,18,28}$ Considering the risks of contamination and transfer of bacteria to a vulnerable site, cultures were taken in several studies. Stored serum was analyzed and it showed no growth in studies, however there were few samples. ${ }^{9,11,18}$ Lagnado et $\mathrm{al}^{24}$ found 13 out of 134 samples to be positive in culture; however, none of the treated patients showed any signs of infection. Immunological mechanisms in the serum might have enough bacteriostatic effect and addition of antibiotics to the solution is generally not recommended.

Immunoglobulin (Ig) deposits have been reported in a patient treated for a PED in a grafted herpetic cornea. The corneal transplant reepithelized, leaving an opacified stromal ring. This was subsequently analyzed as the patient developed allograft rejection and had to be retransplanted. The opacification showed high concentrations of $\operatorname{IgG}, \operatorname{IgM}$, and $\operatorname{IgA}$, which was interpreted as originating from the AS drops. ${ }^{29}$ In this study group, two eyes of one patient with hyper-IgE 
syndrome received treatment for vernal keratoconjunctivitis with shield ulcer. There is a known association between hyper-IgE syndrome and vernal keratoconjunctivitis. ${ }^{30}$ No adverse or positive effects were seen. Compliance to treatment was suspected as being poor in this patient when given in the domestic setting. Theoretically, a higher concentration of IgE, similar to that in serum, could potentially deteriorate the condition. There are, to our knowledge, no case reports written on this subject.

The issue of transferring antibodies or proinflammatory agents from serum to eye of systemically ill patients, suggesting deterioration, could be avoided by using allogenic serum, and umbilical cord serum in particular has been suggested. ${ }^{25,31}$

The indication for treatment is a key question when choosing patients for treatment with AS. Having a patient with epithelial defects, one has to consider the underlying mechanisms behind the finding. In a case of dry eye syndrome and inadequate tear production, AS acts as a biological tear substitute, replacing essential growth factors. While treating a patient with true stem cell deficiency, the serum cannot replace lost cells and expectations should be kept low. However, as is often seen in OSD, multifactorial pathology plays a large role, such as in aniridic keratopathy, where corneal epitheliopathy depends on stem cell deficiency combined with an alteration in the microenvironment of stem cells due to mutation in the PAX6 gene. Applying AS influences this environment and has been shown to give subjective and objective improvement. ${ }^{32}$ In our study, neurotrophic corneas with PEDs seem to respond well to AS treatment. Theoretically, among the growth factors present in serum and tears, NGF might play a greater role and it has also been used in the purified form with some success. ${ }^{2}$ Serum is relatively rich in NGF, compared to tears, with values reaching $468.3 \pm 317.4 \mathrm{pg} / \mathrm{mL}$ and $54 \mathrm{pg} / \mathrm{mL}$, respectively. ${ }^{33}$ Both NGF and AS have provided improved corneal sensitivity. 2,34

\section{Conclusion}

AS has a role in the treatment of OSD when used for the right indications. This retrospective case series cannot evaluate its true effect, especially because several treatments were given simultaneously. Additional randomized controlled trials, investigating AS using a standardized protocol for preparation and evaluation of optimized serum concentrations for various indications, are needed. The advantage of purifying growth factors to ensure low variability among treatments, versus the possible potentiating effect of giving a multitude of factors of variable concentrations as in serum, is to be evaluated.

\section{Acknowledgments}

This work was supported by grants from the Swedish Research Council (number 2011-3132), Swedish government ("Agreement concerning research and education of doctors"; ALF-GBG-145921), Göteborg Medical Society, Marianne and Marcus Wallenberg Foundation, Dr Reinhard Marcuses Foundation, Konung Gustaf V:s och Drottning Victorias Frimurarestiftelse, Hjalmar Svensson Foundation, Greta Andersson Foundation, Herman Svensson Foundation, Ögonfonden, De Blindas Vänner, and Kronprinsessan Margaretas Arbetsnämnd för Synskadade.

\section{Disclosure}

The authors report no conflicts of interest in this work.

\section{References}

1. Lambiase A, Manni L, Bonini S, Rama P, Micera A, Aloe L. Nerve growth factor promotes corneal healing: structural, biochemical, and molecular analyses of rat and human corneas. Invest Ophthalmol Vis Sci. 2000;41(5):1063-1069.

2. Lambiase A, Rama P, Bonini S, Caprioglio G, Aloe L. Topical treatment with nerve growth factor for corneal neurotrophic ulcers. $N$ Engl J Med. 1998;338(17):1174-1180.

3. McClintock JL, Ceresa BP. Transforming growth factor-\{alpha\} enhances corneal epithelial cell migration by promoting EGFR recycling. Invest Ophthalmol Vis Sci. 2010;51(7):3455-3461.

4. Ohashi Y, Motokura M, Kinoshita Y, et al. Presence of epidermal growth factor in human tears. Invest Ophthalmol Vis Sci. 1989;30(8):1879-1882.

5. Ubels JL, Foley KM, Rismondo V. Retinol secretion by the lacrimal gland. Invest Ophthalmol Vis Sci. 1986;27(8):1261-1268.

6. Wilson SE, Liang Q, Kim WJ. Lacrimal gland HGF, KGF, and EGF mRNA levels increase after corneal epithelial wounding. Invest Ophthalmol Vis Sci. 1999;40(10):2185-2190.

7. Nishida T, Ohashi Y, Awata T, Manabe R. Fibronectin. A new therapy for corneal trophic ulcer. Arch Ophthalmol. 1983;101(7):1046-1048.

8. Geerling G, Maclennan S, Hartwig D. Autologous serum eye drops for ocular surface disorders. Br J Ophthalmol. 2004;88(11):1467-1474.

9. Tsubota K, Goto E, Fujita H, et al. Treatment of dry eye by autologous serum application in Sjogren's syndrome. Br J Ophthalmol. 1999;83(4):390-395.

10. Ralph RA, Doane MG, Dohlman CH. Clinical experience with a mobile ocular perfusion pump. Arch Ophthalmol. 1975;93(10):1039-1043.

11. Fox RI, Chan R, Michelson JB, Belmont JB, Michelson PE. Beneficial effect of artificial tears made with autologous serum in patients with keratoconjunctivitis sicca. Arthritis Rheum. 1984;27(4):459-461.

12. Jeng BH. Use of autologous serum in the treatment of ocular surface disorders. Arch Ophthalmol. 2011;129(12):1610-1612.

13. Choi JA, Chung SH. Combined application of autologous serum eye drops and silicone hydrogel lenses for the treatment of persistent epithelial defects. Eye Contact Lens. 2011;37(6):370-373.

14. Ogawa Y, Okamoto S, Mori T, et al. Autologous serum eye drops for the treatment of severe dry eye in patients with chronic graft-versus-host disease. Bone Marrow Transplant. 2003;31(7):579-583.

15. Kojima T, Ishida R, Dogru M, et al. The effect of autologous serum eyedrops in the treatment of severe dry eye disease: a prospective randomized case-control study. Am J Ophthalmol. 2005;139(2):242-246.

16. Noble BA, Loh RS, MacLennan S, et al. Comparison of autologous serum eye drops with conventional therapy in a randomised controlled crossover trial for ocular surface disease. $\mathrm{Br} J$ Ophthalmol. 2004;88(5):647-652. 
17. Poon AC, Geerling G, Dart JK, Fraenkel GE, Daniels JT. Autologous serum eyedrops for dry eyes and epithelial defects: clinical and in vitro toxicity studies. Br J Ophthalmol. 2001;85(10):1188-1197.

18. Tananuvat N, Daniell M, Sullivan LJ, et al. Controlled study of the use of autologous serum in dry eye patients. Cornea. 2001;20(8):802-806.

19. Tsubota K, Goto E, Shimmura S, Shimazaki J. Treatment of persistent corneal epithelial defect by autologous serum application. Ophthalmology. 1999;106(10):1984-1989.

20. Jeng BH, Dupps WJ Jr. Autologous serum 50\% eyedrops in the treatment of persistent corneal epithelial defects. Cornea. 2009;28(10):1104-1108.

21. Pan Q, Angelina A, Zambrano A, et al. Autologous serum eye drops for dry eye. Cochrane Database Syst Rev. 2013;8:CD009327.

22. Lawrence DA. Transforming growth factor-beta: a general review. Eur Cytokine Netw. 1996;7(3):363-374.

23. Cho YK, Huang W, Kim GY, Lim BS. Comparison of autologous serum eye drops with different diluents. Curr Eye Res. 2013;38(1):9-17.

24. Lagnado R, King AJ, Donald F, Dua HS. A protocol for low contamination risk of autologous serum drops in the management of ocular surface disorders. Br J Ophthalmol. 2004;88(4):464-465.

25. Versura P, Profazio V, Buzzi M, et al. Efficacy of standardized and quality-controlled cord blood serum eye drop therapy in the healing of severe corneal epithelial damage in dry eye. Cornea. 2013;32(4):412-418.

26. Bradley JC, Simoni J, Bradley RH, McCartney DL, Brown SM. Timeand temperature-dependent stability of growth factor peptides in human autologous serum eye drops. Cornea. 2009;28(2):200-205.
27. Fischer KR, Opitz A, Boeck M, Geerling G. Stability of serum eye drops after storage of 6 months. Cornea. 2012;31(11):1313-1318.

28. Rocha EM, Pelegrino FS, de Paiva CS, Vigorito AC, de Souza CA. GVHD dry eyes treated with autologous serum tears. Bone Marrow Transplant. 2000;25(10):1101-1103.

29. McDonnell PJ, Schanzlin DJ, Rao NA. Immunoglobulin deposition in the cornea after application of autologous serum. Arch Ophthalmol. 1988;106(10):1423-1425.

30. Butrus SI, Leung DY, Gellis S, Baum J, Kenyon KR, Abelson MB. Vernal conjunctivitis in the hyperimmunoglobulinemia E syndrome. Ophthalmology. 1984;91(10):1213-1216.

31. Versura P, Buzzi M, Giannaccare G, et al. Targeting growth factor supply in keratopathy treatment: comparison between maternal peripheral blood and cord blood as sources for the preparation of topical eye drops. Blood Transfus. Epub 2015 Jul 9.

32. Lopez-Garcia JS, Rivas L, Garcia-Lozano I, Murube J. Autologous serum eyedrops in the treatment of aniridic keratopathy. Ophthalmology. 2008;115(2):262-267.

33. Matsumoto Y, Dogru M, Goto E, et al. Autologous serum application in the treatment of neurotrophic keratopathy. Ophthalmology. 2004;111(6):1115-1120.

34. Joo MJ, Yuhan KR, Hyon JY, et al. The effect of nerve growth factor on corneal sensitivity after laser in situ keratomileusis. Arch Ophthalmol. 2004;122(9):1338-1341.
International Medical Case Reports Journal

\section{Publish your work in this journal}

The International Medical Case Reports Journal is an international, peer-reviewed open-access journal publishing original case reports from all medical specialties. Previously unpublished medical posters are also accepted relating to any area of clinical or preclinical science. Submissions should not normally exceed 2,000 words or

\section{Dovepress}

4 published pages including figures, diagrams and references. The manuscript management system is completely online and includes a very quick and fair peer-review system, which is all easy to use. Visit http://www.dovepress.com/testimonials.php to read real quotes from published authors. 